\section{References}

1. Russell KA, Fass DN, Specks U. Antineutrophil cytoplasmic antibodies reacting with the pro form of proteinase 3 and disease activity in patients with Wegener's granulomatosis and microscopic polyangiitis. Arthritis Rheum. 2001;44:463-8.

2. Rasmussen N. Management of the ear, nose, and throat manifestations of Wegener's granulomatosis. Curr Opin Rheumatol. 2001;13:3-11.
3. Kreutzer C, Vive JD, Oppido G, Kreutzer J, Gauvreau K, Freed M, et al. Twenty-five-year experience with Rastelli repair for transposition of the great arteries. J Thorac Cardiovasc Surg. 2000;120:21123.

4. Nottin R, Grinda JM, Anidjar S, Folliguet T, Detroux M. Coronarycoronary bypass graft: an arterial conduit-sparing procedure. J Thorac Cardiovasc Surg. 1996;112;1123-30.

5. Ott DA, Cooley DA. The difficult proximal coronary anastomosis. Cardiovasc Dis Bull Tex Heart Inst. 1979;6:55-8.

\title{
Acute graft failure caused by an intracoronary shunt in minimally invasive direct coronary artery bypass grafting
}

Hironori Izutani, MD, PhD, and Inderjit S. Gill, $\operatorname{FRCS(C),~Cleveland,~Ohio~}$

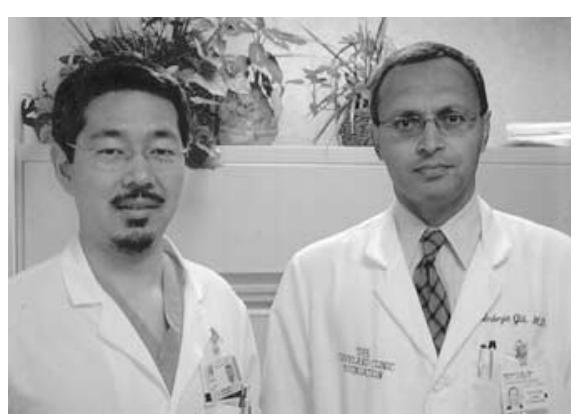

Izutani (left) and Gill (right)
A $\mathrm{n}$ intracoronary shunt is often used to maintain distal perfusion during off-pump coronary artery bypass grafting. We report the case of a patient who had acute graft occlusion caused by such a shunt as a result of intimal injury to the coronary artery during minimally invasive direct coronary artery bypass grafting (MIDCAB).

\section{Clinical Summary}

The patient was an 84-year-old woman who underwent cardiac catheterization after having abnormal results of a stress test before planned orthopedic surgery. Cardiac catheterization revealed triple-vessel coronary artery disease with $50 \%$ to $60 \%$ lesion of the left main trunk, mild and diffuse disease of the left anterior descending (LAD) coronary artery, normal left ventricular wall motion, and an ejection fraction of $79 \%$. Treatment options were discussed, and the patient was referred for a hybrid procedure, an elective MIDCAB to be followed by percutaneous intervention to the right coronary and circumflex system.

The patient underwent MIDCAB through a left minithoracotomy. The operative technique has been previously discussed

From the Department of Thoracic and Cardiovascular Surgery, Cleveland Clinic Foundation, Cleveland, Ohio.

Received for publication May 13, 2002; accepted for publication June 13, 2002.

Address for reprints: Inderjit S. Gill, FRCS(C), Department of Thoracic and Cardiovascular Surgery, Cleveland Clinic Foundation, 2500 MetroHealth Dr, Third Floor Hamann Building, Cleveland, OH 44109-1998 (E-mail: gillis@ccf.org).

J Thorac Cardiovasc Surg 2003;125:723-4

Copyright $\odot 2003$ by The American Association for Thoracic Surgery

$0022-5223 / 2003 \$ 30.00+0$

doi: $10.1067 / \mathrm{mtc} .2003 .142$ elsewhere. ${ }^{1}$ The diameter of the left internal thoracic artery (LITA) was $1.5 \mathrm{~mm}$. Stabilization of the target vessel was achieved with the Genzyme Immobilizer (Genzyme Corporation, Cambridge, Mass). Coronary arteriotomy was performed, and a $1.5-\mathrm{mm}$ intracoronary shunt (Guidant Axius Coronary Shunt; Guidant, Cupertino, Calif) was placed with some difficulty (Figure 1). The anastomosis was carried out with 7-0 Prolene running suture (Ethicon, Inc, Somerville, NJ). After the last stitch was placed, the intracoronary shunt was carefully taken out and the suture was tied. Graft flow measurements were carried out with a Transonic Flow-QC meter (Transonic Systems, Inc, Ithaca, NY). Although the graft pulsation was good, the graft flow measurement showed a poor diastolic flow pattern and insufficient blood flow at $5 \mathrm{~mL} / \mathrm{min}$. The anastomosis was therefore taken down and examined. No reason was found for graft malfunction. A $1.5-\mathrm{mm}$ vessel probe was passed through distally and proximally from the arteriotomy. The anastomosis was then carefully redone in the same fashion. However, a repeated graft flow measurement was still unsatisfactory with poor graft flow. The patient was taken for urgent cardiac catheterization, and the angiogram showed total occlusion of the LITA graft at the mid portion and total occlusion of the mid LAD.

The patient was taken back to the operating room and underwent a median sternotomy and conventional cardioplegic arrest. The anastomosis was taken down again and examined. Fresh thrombus formation was found blocking the blood flow at the anastomotic site, and this was removed cautiously. It appeared to have occluded both the proximal LAD and the LITA graft. The LAD arteriotomy was extended proximally and distally. Intimal lacerations were seen $5 \mathrm{~mm}$ proximal and distal to the arteriotomy (Figure 2, $A$ ), which coincided with the bulbous ends of the intracoronary shunt (Figure 1). Although no abnormality was found in the LITA graft at this site, it was abandoned for regrafting. The LAD was divided, two separate 


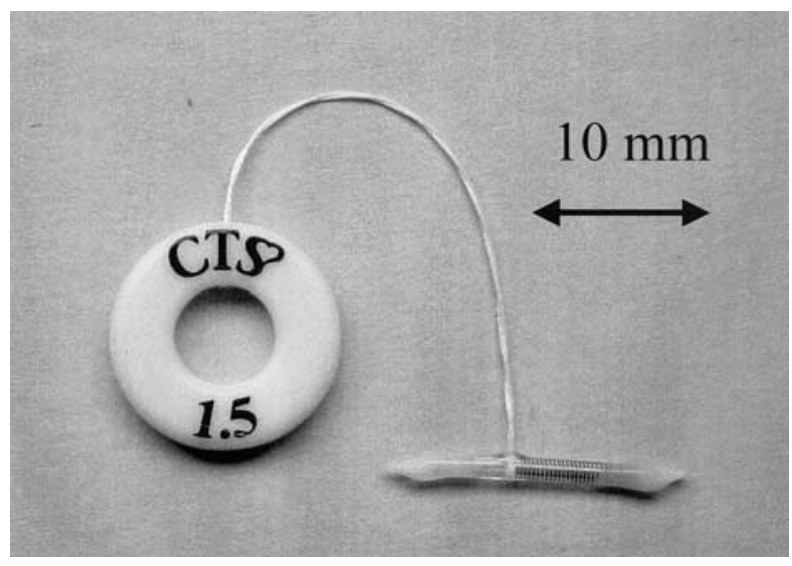

Figure 1. Intracoronary shunt with diameter of $1.5 \mathrm{~mm}$ used to perform coronary anastomosis.

reverse saphenous venous grafts were anastomosed to the proximal and distal divided segments (Figure 2, B). Two separate reverse saphenous venous grafts were also anastomosed to the posterior descending artery and the lateral circumflex artery. Proximal anastomoses of the saphenous venous grafts were placed on the ascending aorta. There were no significant electrocardiographic or enzyme changes after the operation. The patient's postoperative course was unremarkable, and she was discharged on the sixth postoperative day.

\section{Comment}

With currently available stabilization systems and intracoronary shunts, MIDCAB can be performed safely with satisfactory graft patency even in elderly patients. ${ }^{2,3}$ The use of an intracoronary shunt prevents deterioration in ventricular function and arrhythmias, presumably by maintaining distal myocardial perfusion. 4,5 However, there are few data available regarding complications caused by the use of such shunts.

Careful insertion and removal should be undertaken to prevent vessel injury. Selection of a properly sized shunt is also important in obtaining a blood-free surgical field and in preventing injury. The incidence of vessel injury caused by intracoronary shunt placement is extremely low with skilled surgical technique.

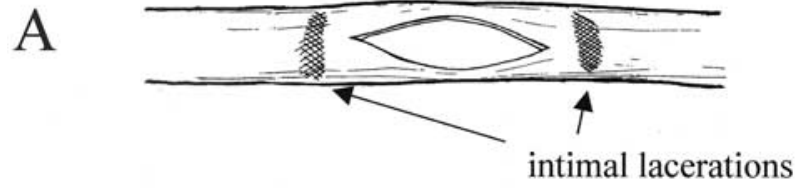

B

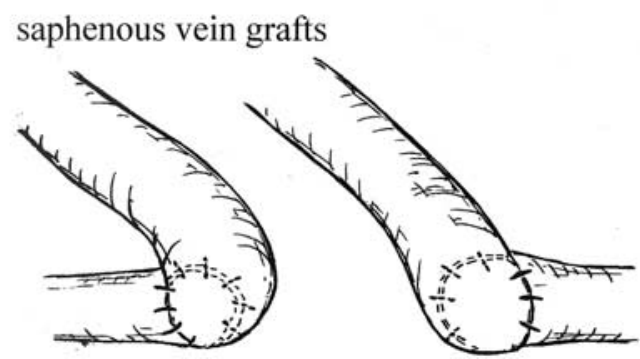

Figure 2. A, Sites of intimal laceration seen on extending the arteriotomy. B, Divided ends of the LAD artery with separate proximal and distal saphenous venous bypasses.

This report highlights the utility of intraoperative flow measurement to reveal acute graft failure in beating-heart surgery, allowing timely intervention. It also highlights the potential of traumatic intimal injury by intracoronary shunts. Extra caution should be taken in frail and elderly patients with diffusely atherosclerotic and fragile coronary arteries.

\section{References}

1. Gill IS, FitzGibbon GM, Higginson LA, Valji A, Keon WJ. Minimally invasive coronary artery bypass: a series with early qualitative angiographic follow-up. Ann Thorac Surg. 1997;64:710-4.

2. Watanabe $\mathrm{Y}$, Koyama N. Minimally invasive direct coronary artery bypass (MIDCAB). Ann Thorac Cardiovasc Surg. 2000;6:356-60.

3. Mehran R, Dangas G, Stamou SC, Pfister AJ, Dullum MK, Leon MB, et al. One-year clinical outcome after minimally invasive direct coronary artery bypass. Circulation. 2000;102:2799-802.

4. Lucchetti V, Capasso F, Caputo M, Grimaldi G, Capece M, Brando G, et al. Intracoronary shunt prevents left ventricular function impairment during beating heart coronary revascularization. Eur J Cardiothorac Surg. 1999;15:255-9.

5. Rivetti LA, Gandra SM. Initial experience using an intraluminal shunt during revascularization of the beating heart. Ann Thorac Surg. 1997; 63:1742-7. 